\title{
El libro electrónico y digital en la ecología informacional: avances y retos
}

\author{
Por Francisco-Javier García-Marco
}

\begin{abstract}
Resumen: Se analiza la problemática, el contexto y el concepto del libro electrónico; las tendencias actuales en el desarrollo del libro electrónico; las ventajas y desventajas competitivas frente al libro tradicional; y su impacto en la ecología de la producción, conservación y distribución del libro y en los diferentes agentes implicados, tanto en el mercado como en las bibliotecas.

Palabras clave: Libro, Libro electrónico, Libro digital, Análisis comparativo, Evolución, Impacto.

Abstract: The problematics, context, concept and design trends of electronic books are discussed. The advantages and disadvantages of the electronic book versus the traditional one are analyzed. Finally, its impact in the ecology of

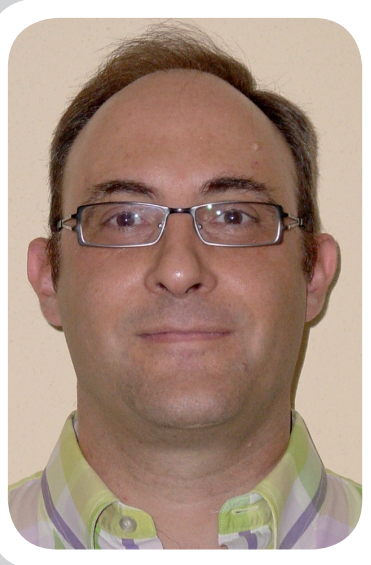

Francisco Javier García Marco es doctor en Filosofía y Letras y profesor titular de universidad del Área de Biblioteconomía y Documentación de la Universidad de Zarago$z a$, desde donde enseña, investiga y escribe sobre el impacto de las nuevas tecnologías de la información y la comunicación en los servicios de información y documentación y en su entorno social. Organiza los Encuentros internacionales sobre sistemas de información y documentación (Ibersid) y dirige la revista "Scire: representación y organización del conocimiento".
\end{abstract}

book production, preservation and dissemination and in its different stakeholders is assessed, both market-oriented firms and libraries.

Keywords: Books, Electronic books, Digital books, Comparative analysis, Evolution, Impact.

García-Marco, Francisco-Javier. "El libro electrónico y digital en la ecología informacional: avances y retos”. En: El profesional de la información, 2008, v. 17, n. 4, julio-agosto, pp. 373-389.

DOI: 10.3145/epi.2008.jul.02

\section{Aporía del libro en la era de la información digital}

En torno al libro electrónico se desenvuelve una de las aporías más significativas de la sociedad digital: desde hace más de dos décadas, el libro en papel resiste con éxito el envite de su competidor digital, el libro electrónico.

Mientras el resto del mundo de la información lleva décadas digitalizándose a pasos agigantados gracias a los avances de las tecnologías de la información y de la comunicación, el libro -el emblema de la cultura del papel-resiste asombrosamente los embates de la nueva cultura tecnológica, de la que, sin embargo, se beneficia sin complejos en su producción -la edición- y distribución -con un caso extremo en las librerías digitales como Amazon-.

En su generalidad, el documento digital triunfa. Los documentos se crean con programas de ordenador, se almacenan en ordenadores, se transmiten mediante redes telemáticas y se consultan mediante ordenadores. Sin embargo, el libro, el icono de la cultural del papel, sigue resistiendo aparentemente intacto.

La digitalización ha triunfado en la imagen fija, el vídeo casero y comercial, la música y, recientemente, en los mapas. También se expande ya sin apenas resistencia en el mundo de la información periódica, tanto prensa como revistas generalistas y especializadas -se trata de una información para estar al día para la que la velocidad de acceso es una gran ventaja competitiva-, aunque aquí las proporciones están todavía en tablas, y, por supuesto, en el de la información comercial. La televisión está al borde del "apagón analógico", en 2010. En este panorama, el mundo del libro parece el único bastión del viejo universo de los medios no digitales.

Es cierto que la Red se ha ido poblando de libros digitales gracias a la financiación de los gobiernos, el esfuerzo de las instituciones públicas y, más recientemente, de algunas grandes corporaciones como Amazon, Google y Microsoft. Sin embargo, las estadísticas 
indican que el libro se sigue comercializando y leyendo fundamentalmente en papel.

El libro electrónico es sin duda el frente más significativo que resiste con más éxito ante una de las tendencias que definen nuestro momento cultural: la digitalización, el prerrequisito para la automatización del trabajo informacional.

En un artículo sobre el libro electrónico de referencia en nuestro país publicado en esta misma revista, Lluís Codina (1999) sintetizaba la solución a esta paradoja con una acertada sinécdoque: los libros digitales "no desplazarán al papel de su lugar privilegiado en la cultura hasta que los monitores de ordenador no asuman las propiedades ergonómicas del papel". O, como han insistido otros autores (v. g. Hill, 1999), el libro en papel es una herramienta extraordinaria y evolucionadísima que sólo podrá ser suplantada por otro instrumento que sea tan bueno como él, y que lo supere.

Hoy, diez años después, la emergencia del libro electrónico y su introducción en la ecología del libro tradicional sigue siendo uno de los temas más polémicos en la Biblioteconomía, la Ciencia de la Información, la Librería y las Ciencias del Libro (Pedraza, 2005). Aunque el libro electrónico no ha triunfado sobre el libro en papel, ha habido grandes avances en las tecnologías de soporte y uso, en los formatos de codificación, en los modelos de comercialización y, sobre todo, en los últimos cinco años está creciendo significativamente su uso real.

Las implicaciones del despegue del libro electrónico para usuarios, escritores, editores, distribuidores y conservadores son enormes. Si bien tanto el libro en papel como el digital pueden tener el mismo contenido y cada vez más se producen igual, luego se comercializan, conservan, reproducen y se leen de forma muy distinta. Estas diferencias ponen en crisis el concepto de biblioteca y librería tradicionales, que son los dos cauces de distribución fundamentales de la cultura del libro, y dos de las industrias culturales más significativas.

\section{Definición de libro}

Como señala Gall (2005), hay muchos mitos sobre los libros electrónicos y uno de los más importantes es que resulta fácil definirlos.

Un problema previo al análisis de cualquier cosa es definirla. No es difícil definir un libro prototípico: una monografía impresa en un conjunto de hojas de papel encuadernadas al lomo formando un volumen. Lo que ocurre es que el uso del concepto libro -central en nuestra cultura- alcanza usos matizados, analógicos y metafóricos que extienden extraordinariamente su territorio: los periódicos y revistas se suelen incluir en el territorio del libro, así como ejemplares menos prototípicos como los audiolibros; en el mundo de la Ciencia de la Información es frecuente extender el concepto de libro digital a casi cualquier documento disponible en la web. Pero la confusión sobre el libro precede a los libros electrónicos.

Desde un punto de vista clásico, el Diccionario de la Real Academia (2001-2008) resume bien los tres parámetros de una definición del libro y el conflicto entre ellos:

1. El que se refiere a la forma o soporte: "Conjunto de muchas hojas de papel $u$ otro material semejante que, encuadernadas, forman un volumen".

2. El que se refiere a su contenido: "Obra científica, literaria o de cualquier otra índole con extensión suficiente para formar volumen, que puede aparecer impresa o en otro soporte".

3. El que se refiere a la constricción legal: "Para los efectos legales, en España, todo impreso no periódico que contiene 49 páginas o más, excluidas las cubiertas".

4. Hay contradicciones entre la definición basada en la forma y en el contenido, prevaleciendo en último término la forma: "Cada una de ciertas partes principales en que suelen dividirse las obras científicas o literarias, y los códigos y leyes de gran extensión".

Otro documento de referencia, la Ley de la lectura, del libro y de las bibliotecas (España, 2007) nos puede servir para constatar la evolución que ha experimentado el concepto de libro como resultado del impacto de internet y de los soportes digitales. En su preámbulo se reconoce que la Ley:

"Surge como medida que atiende la pluralidad de matices que encierra el concepto de «lectura» y como reconocimiento de la diversidad de formatos que ofrece el concepto de «libro». Dado que es necesaria una adecuación a la nueva realidad, es preciso redefinir algunos conceptos esenciales, y ampliar el campo semántico de los mismos y que se imponen necesariamente a la nueva realidad, objeto de esta Ley".

Y en su artículo segundo se sintetiza una definición comprensiva y abierta:

"Libro: obra científica, artística, literaria o de cualquier otra índole que constituye una publicación unitaria en uno o varios volúmenes y que puede aparecer impresa o en cualquier otro soporte susceptible de lectura. Se entienden incluidos en la definición de libro, a los efectos de esta Ley, los libros electrónicos y los libros que se publiquen o se difundan por internet o en otro soporte que pueda aparecer en el futuro, los materiales complementarios de carácter impreso, visual, audiovisual o sonoro que sean editados conjuntamente con el 
libro y que participen del carácter unitario del mismo, así como cualquier otra manifestación editorial”.

\section{Definición de libro electrónico}

Ahora bien, cuando se habla de libro electrónico, también se acentúa la confusión entre mensaje y soporte (figura 1). Muchos utilizan el término libro electrónico para referirse a la codificación digital-normalmente en un archivo de ordenador- del mensaje contenido en un libro tradicional: un texto o una colección de textos relacionados que se ofrecen conjuntamente al lector. Dentro de este enfoque se pueden distinguir también dos tendencias: los que equiparan libro electrónico con la información disponible en internet, que efectivamente es información pública, semejante en este aspecto al libro publicado; y los que limitan el concepto de libro electrónico a un formato especial de documento digital que cumple las funcionalidades del libro tradicional en cuanto a aspecto y uso. Por fin, otros se refieren al nuevo soporte: un dispositivo para acceder, leer y usar esos libros. También aquí coexisten dos realidades bien diferentes: por un lado, los dispositivos dedicados, específicamente diseñados, los "libros electrónicos" propiamente dichos, como el Kindle de Amazon; y, por el otro, las aplicaciones de lectura y utilización de libros en formato digital, como Adobe Acrobat, para dispositivos de carácter general.

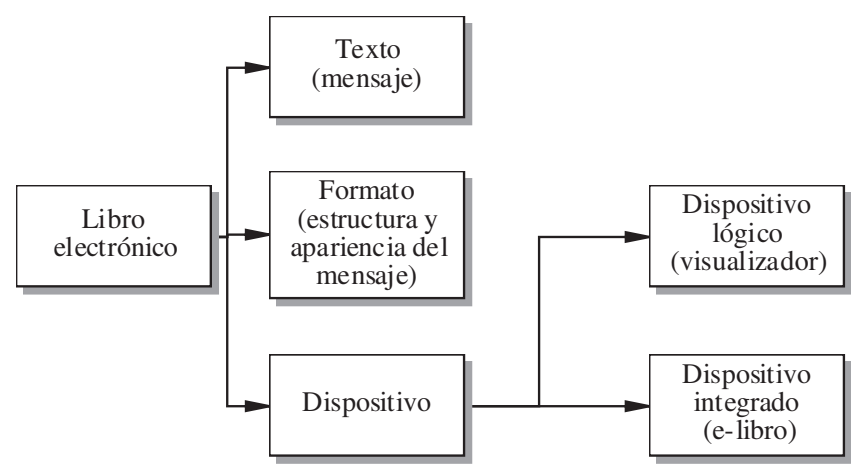

Figura 1. Los diversos sentidos del concepto de libro electrónico

Para evitar las confusiones terminológicas, sugerimos usar "libro digital" para designar a los formatos digitales equivalentes al libro -aunque puedan tener características más evolucionadas-, y utilizar el término "libro electrónico" o "e-libro" -que implica la utilización de circuitos electrónicos- para referirnos a los dispositivos electrónicos que sirven para descargar, leer, utilizar y, cada vez más, almacenar los "libros electrónicos". Resulta necesario, también, aceptar que un ordenador con un visualizador de libros digitales funciona como un libro electrónico, aunque no es sólo un libro electrónico. Por otro lado, para el concepto extendido de libro electrónico como cualquier conjunto de datos reunido por un autor o editor para su difusión conjunta, proponemos usar el más general de "documento digital", bien entendido que el documento digital puede contener otros documentos digitales y puede agruparse en estructuras mayores, como, por otra parte, ocurre en el mundo del libro impreso que también se estructura en colecciones, obras en varios volúmenes, libros encuadernados, monografías, obras publicadas conjuntamente, contribuciones, capítulos, etc.

En cualquier caso y toda vez que los autores utilizan toda esta terminología de forma flexible, es necesario insistir en que al hablar de libros electrónicos se está aludiendo a realidades diferentes; y que cuando se desea descender a actividades analíticas -como, por ejemplo, la evaluación de las tecnologías-, es necesario clarificar con cuidado de qué se está hablando. Sirva un ejemplo para ilustrar el tipo de confusiones que se suelen producir: Se insiste normalmente que el libro electrónico es más durable que el de papel. En principio es fácil convenir en que la codificación digital es más estable. Sin embargo, el hardware de los libros electrónicos es mucho más frágil y obsolescente, y, al menos hasta ahora, los formatos específicos de los ficheros también están en continua modificación, provocando problemas de lectura de los ficheros más antiguos. Finalmente, la conservación de los documentos digitales, muy sencilla en teoría y poco costosa en términos de replicación, ha demostrado constituir un problema institucional, social y político de primera magnitud que está lejos de ser resuelto. De hecho, casi todos los autores están de acuerdo en que se pierde mucha más información digital que la que se perdía en los soportes físicos tradicionales. Así que es cierto que la información digital no se degrada "lógicamente", pero los formatos y soportes digitales no comparten esas propiedades.

\section{Forma y función}

El éxito del libro como instrumento y fenómeno social reside en la óptima relación que existe entre su forma y su función, que denota que estamos ante un artefacto cultural altamente evolucionado. Un objeto profundamente integrado en la sociedad, en la que hay industrias enteras -las bibliotecas y centros de documentación son una de ellas- dedicadas a hacerlo posible y a extraer de él el máximo provecho. Por ello, la comprensión y el diseño del libro electrónico parten del desentrañamiento cuidadoso de la función del libro y de las formas que han ido surgiendo históricamente para dar cuenta de ella, de su función, en diferentes ambientes. Se trata de estudiar, por así decirlo, la ecología del libro, en la que se está introduciendo una nueva especie que, posiblemente, terminará por desplazarlo.

La función: transmisión del saber y otros usos del libro. 
El libro es un tipo de documento. Y el documento es nada más y nada menos que una tecnología de comunicación cuya función es permitir al emisor $-\mathrm{y}$ al receptor, subsidiariamente- que el mensaje comunicativo trascienda los límites del espacio y el tiempo que atenazan a la comunicación oral presencial. En la cultura oral el mensaje sólo puede preservarse mediante la reverberación, mediante la repetición del mensaje de persona a persona. Gracias al documento, como señala José López-Yepes (1981), el mensaje se fija en un soporte. Queda así disponible para su consulta, y, si su tamaño y características lo permiten, para su transporte. Pero no es sólo cuestión de eficacia -transmisión en el tiempo y el espacio-, sino también de eficiencia: la transmisión del mensaje por receptor cuesta menos esfuerzo y recursos, y se realiza en menor tiempo.

Los inmensos efectos cuantitativos que introduce el documento en la duración y diseminación de los mensajes producen unos efectos cualitativos de no menor importancia. Por un lado, el documento facilita y acelera los procesos de intercambio cultural. Por otra parte, el mensaje documentado gana autonomía respecto a sus emisores y receptores inmediatos, a los que transciende, ayudando a generar ese "tercer mundo" que, junto a la naturaleza y el conocimiento, rodea al ser humano (Popper, 1979). Recíprocamente, la sociedad - especialmente, la parte de ella educada- puede liberar energías dedicadas a la repetición de los mensajes que merecen ser repetidos, preservados. El lector, por su parte, gana distancia respecto al mensaje, liberándose de la presencia fática y retórica del emisor -de su influencia inmediata y directa-.

La especificidad del libro respecto a otros tipos de documentos es que permite difundir y preservar en un soporte móvil, ligero y compacto un mensaje compuesto de texto e ilustraciones de amplia extensión, fundamentalmente relatos o conjuntos de relatos relacionados, de carácter lúdico o educativo, con fines religiosos, jurídicos, de entretenimiento o de formación filosófica y científica -cuando ésta fue tomando cuerpo independiente-. El libro se convierte en el instrumento de la cultura "letrada" -educada-, en la herramienta de los que tienen la función preeminente de crear, transmitir y aplicar la cultura almacenada en ellos, y que ven recompensada esa preeminencia -por lo general- con una posición social y económica privilegiada.

Frente al "escuchar", muy ligado al adoctrinamiento y la propaganda, al estar conectado con la cultura oral y omnipresente de la tribu -dicho esto sin connotaciones negativas, sino constatando tan sólo una naturaleza y una modalidad distintas de ser en sociedad-, el "leer" está ligado a un mayor grado de libertad y autonomía del individuo. Al ser la lectura un acto íntimo -si no, deviene en escucha- la relación con el mensaje puede volverse más reflexiva, mucho más si la lectura se apoya en la escritura. El mecanismo es muy sencillo, básicamente la lectura individual permite crear espacios en la recepción del mensaje para la reflexión, la crítica y la búsqueda de evidencias. Por ello, el lectorescritor de libros -en general como persona culta o en particular como jurista, literato, científico o técnico-es lo contrario de una correa de transmisión: Es un ser autónomo que adquiere, crea y aplica conocimiento, ganando libertad personal y también una extraordinaria ventaja competitiva sobre sus semejantes al administrar uno de los recursos nucleares de la reproducción social, esto es, la cultura documentada.

Se comprende que el libro sea, por tanto, un icono del poder basado en el conocimiento. Y también, en consonancia, que los movimientos liberadores hayan tenido siempre en el libro, como símbolo de la cultura y la educación -en el sentido de conocimiento que merece ser preservado-, uno de sus frentes fundamentales. El ansia de liberación a través de la lectura ha partido de los individuos y las familias, y también de los grupos, sirviéndose tanto de la industria y el comercio como del Estado. Algunos hitos que jalonan esa historia de progreso son las escuelas municipales, la lectura privada de la Biblia y los devocionarios, la prensa, la biblioteca pública... En nuestros tiempos, el territorio del conocimiento documentado se está trasladando masivamente a un nuevo espacio, la internet, el territorio por excelencia del libro electrónico.

Sin embargo, para comprender el papel del libro en nuestra sociedad y los cambios que se están produciendo en torno a él, hay que dar un paso más y ser analítico. La propia función cognitiva se despliega en un conjunto de especialidades que se ven de forma distinta desde el punto de vista del lector, el autor y los que median entre ellos. Hay libros de referencia sobre personas, entidades, lugares y otros documentos; de doctrina y estudio; de puesta al día - prontuarios-; de debate, provocación y propaganda -ensayos y panfletos-; de inmersión en experiencias sensoriales, estéticas y narrativas -poesía y literatura-... Aunque se parecen mucho, las diferentes familias de libros se manejan y se leen de forma distinta, y eso se está reflejando en la propia evolución del libro electrónico.

El libro también tiene una función semiótica integrada en el imaginario cultural, que le aporta un valor también idiosincrásico. El libro es un objeto bello, insertado en una experiencia varias veces centenaria de placer. Por ello, la lectura de un libro es una experiencia en sí misma, no sólo un cauce para transmitir conocimiento.

Como en otros aspectos de la adopción tecnológica, no se debe descartar que existan límites de carácter sociocultural a la adopción total de las nuevas tecnologías 


\section{"El libro es un objeto bello, y su lectura es una experiencia de placer, no sólo un cauce para transmitir conocimiento"}

del libro. Una parte importante de la población podría desear utilizar libros de la misma manera que mucha gente, especialmente en los países nórdicos, continua utilizando la iluminación mediante velas para crear un ambiente especial.

De estas funciones primarias, deriva otra fundamental: como cualquier objeto valioso, el libro es relativamente escaso, cuesta escribirlo, producirlo y difundirlo, exige un trabajo profesional en muchos momentos de su ciclo de vida y en muchos de sus entornos, y, en consonancia, adquiere un valor de cambio. En función de este valor comercial, el libro es un objeto económico que se compra, vende, intercambia, regala y presta entre comerciantes, instituciones y particulares. Es también un objeto hermoso para muchos que se adquiere y comercia por coleccionismo.

\section{Forma del libro: difícil camino hacia el libro electrónico}

La forma del libro ha ido avanzando a lo largo de los siglos de acuerdo con su función: una herramienta móvil para almacenar mensajes largos de la forma más eficaz y eficiente posible. No es cuestión de repasar aquí esta historia, pero sí de dar algunas pinceladas que muestren como la tecnología del libro ha ido evolución para conseguir sus fines de la forma más efectiva: En Oriente Medio, la tabla de arcilla dejó paso al papiro, más ligero. En él, los textos largos se guardaban conjuntamente en rollos, denominados biblos por los griegos por la ciudad fenicia desde la que se exportaban. Los conquistadores romanos les asignaron el nombre de liber, que ellos habían utilizado para otra tecnología documental móvil menos evolucionada: la corteza de los árboles. A partir del siglo III, el códice de hojas encuadernadas fue imponiéndose lentamente al ser más fácil de manejar. La imprenta lo encontró casi en su forma actual y permitió la primera gran automatización en la historia del libro: la de su producción.

Bill Hill (1999) analiza con detalle en un informe que sirvió de base para el desarrollo del Microsoft Reader cómo el libro se fue optimizando progresivamente para el aparato visual humano en aspectos como la estructura de la página, la tipografía, etc., y explica ya entonces por qué es tan difícil reproducir la experiencia lectora, y por qué la web y las pantallas hacen la lectura difícil y llena de distracciones, que son el enemigo natural de la "magia de la lectura", "territorio de la lec- tura" en palabras de Codina (1999). La optimización de la lectura es, además, algo que se investiga desde hace años en disciplinas como la edición o la psicología lectora, y sus hallazgos reflejan cómo el éxito lector depende del documento, el lector y el entorno, e incluye procesos físicos, fisiológicos, de atención, concentración y comprensión, que se ven también afectados por la tecnología electrónica.

El esfuerzo por digitalizar la lectura se ha ido entretejiendo con dos hebras diferentes en un territorio de rápido cambio tecnológico, móvil y resbaladizo, sujeto a una fuerte competencia y continua innovación. Las tendencias de desarrollo han sido básicamente dos: por un lado, convertir los ordenadores de propósito general en dispositivos más aptos para la lectura de documentos; por el otro, el diseño de ordenadores específicamente dedicados a la lectura de libros.

La primera de esas hebras, que podremos llamar "generalista", se compone a su vez de dos hilos diferentes. En primer lugar, el proyecto de crear un escritorio automatizado que ponga al alcance del usuario cualquier tipo de documento. En realidad, el libro electrónico en cuanto soporte ha sido desde muy pronto el ordenador personal. Toda la historia del hipertexto y de la propia evolución de los interfaces de usuario gira entorno a este concepto de escritorio electrónico al que llegan los documentos electrónicos. Esta línea tiene sus hitos en el Memex de Bush en 1945, el Augment de Doug Engelbart de 1962, el Xanadú de Ted Nelson de 1965... (García, 1992). Sin embargo, el ordenador de mesa adolece de un problema grave cuando se compara con el libro en papel: tiene una portabilidad difícil y sujeta a muchas condiciones, si es que la tiene en cualquier caso.

Por eso, esta tendencia "generalista" ganó una importante batalla al papel con el desarrollo de los ordenadores portátiles, que acercaban la potencia de computación a la experiencia del libro y el cuaderno, y que se concibieron desde el primer momento como instrumentos de conexión móviles. De hecho, el libro-cuaderno ha sido el principal referente de la informática móvil, como bien denota la expresión inglesa notebo$o k$ para referirse a ellos. Un ejemplo de estas primeras concepciones es el Dynabook de Alan Kay de 1968.

El segundo hilo de la hebra "generalista" es la convergencia de las telecomunicaciones con el mundo de los ordenadores. La invención de la internet -con los hitos de Arpanet en 1969, la adopción del protocolo TCP/IP en 1982 y la fusión con Nsfnet en 1990- y, especialmente, de la World Wide Web en 1991 -que la hizo "usable"-, son los dos hitos fundamentales, a los que en los últimos años hay que sumar el despegue de la llamada web social o Web 2.0. La automatización de las comunicaciones humanas ha creado de hecho un 
entorno comunicativo de segundo orden respecto a las que permitía la cultura del papel y celuloide, y constituye una de las grandes oportunidades de futuro para el mundo del libro. La web semántica busca estrechar la relación entre la computabilidad de los ordenadores en red en el marco de la internet como tecnología de comunicación documental e interactiva.

En este marco tecnológico, compuesto por el ordenador conectado a internet, surgieron casi inmediatamente los grandes proyectos de bibliotecas digitales, cuyo objetivo era digitalizar y poner en red la cultura del libro. En fechas tan tempranas como 1971 se puso ya en marcha el proyecto Gutenberg. Tras el éxito de la WWW, se multiplican las iniciativas, especialmente a finales de los noventa, entre las que destacan, por ejemplo, el Universal Library Project, conocido como el Million Books Project en 2002 o, en nuestro país, la Biblioteca Virtual Miguel de Cervantes en 1999.

La segunda hebra a la que nos referíamos antes ha sido la de desarrollar dispositivos dedicados para la lectura de libros electrónicos, apoyándose en el desarrollo de la industria de los ordenadores portátiles, pero con la pretensión de adaptarlos mejor a la actividad lectora.

Los primeros productos exitosos tuvieron que ver con la publicación de diccionarios y algunas obras de referencia en dispositivos más emparentados con las calculadoras que con los ordenadores portátiles, generando uno de los primeros mercados de nicho para los libros electrónicos. La empresa Franklin fue una de las pioneras en ese segmento a partir de 1986. Podríamos denominar a estos dispositivos la generación cero.

En 1990 Sony inaugura la primera generación de libros electrónicos sacando al mercado el primer libro electrónico propiamente dicho, el Data Discman, inspirado en el éxito del Walkman, su legendario reproductor de música portátil. Era un dispositivo de mano que funcionaba con cd-roms, una batería de tres horas y una pantalla de cristal líquido capaz de mostrar diez líneas, pesaba algo menos de medio kilo, ofrecía 20 títulos -casi exclusivamente referencia-, y se vendía por entre 390 y 550 dólares en Estados Unidos. Para él, Sony desarrolló el Sony Electronic Book Authoring System. En 1996 ajusta la marca a Bookman, y dota a su producto de una pantalla más grande, un procesador compatible con DOS y sonido, pero a un precio cercano al de un portátil.

En los últimos años del siglo XX se comercializa la segunda generación de libros electrónicos: el Rocket ebook de Nuvomedia en 1998, el Softbook de Softbooks Press y el EveryBook de EB (finales de 1998) (v. Eíto, 2002). Estos dispositivos llegan en plena explosión de la burbuja tecnológica buscando un éxito semejante al conseguido en la música. Su principal novedad fue la conexión a internet, aunque Rocket era todavía un aparato de transición que lo hacía a través de un PC. Everybook añadía la novedad de dos pantallas enfrentadas como un libro, y, sobre todo, del color, pero con un precio muy alto y un peso de casi $2 \mathrm{~kg}$. Todos ellos adoptaron html y pdf como los formatos de referencia. Detrás se organizaron ya los primeros servicios avanzados de librería electrónica, cuya evolución merecería un artículo aparte.

Debido a que estos dispositivos se asemejaban mucho a las PDA y table-PC, pero sin su economía de escala y versatilidad, empezaron rápidamente a perder la batalla por un nicho específico. En particular los PDA se convirtieron pronto en la principal plataforma de comercialización de libros electrónicos, especialmente en Japón. Durante estos años primeros del siglo, el desarrollo del libro digital ha ido ligado al de los artilugios informáticos portátiles. Así, por ejemplo, en el título de una ponencia del año 2000, Van Roekel (2001) equiparaba los libros electrónicos con el acceso portátil a la información digital.

Con la segunda generación aparecen las primeras librerías digitales importantes: NetLibrary (1999), Questia (2000) y ebrary (2001), Ebook Library (EBL, 2004) y MyLibrary (2004). Es significativo de las dificultades para crear un auténtico mercado de consumo que la primera y la tercera vendan actualmente sólo a través de bibliotecas actualmente. A partir de 2005 entran las grandes editoriales: Elsevier, Oxford University Press, Springer, y Taylor \& Francis (Ferguson, 2006, 2007).

Desde 2006, el libro electrónico de la tercera generación -representado por dispositivos como el Portable Reader de Sony, eBook Reader (REB) de Gemstar, y Kindle de Amazon, aparecido en 2007- ha vuelto a recuperar una ventaja competitiva respecto a los ordenadores de diverso tipo gracias a una nueva invención. Se trata de la tinta electrónica electroforética -de $E$ Ink (1997), un offspring del Massachusetts Institute of Technology (MIT)-, una tecnología capaz de proporcionar una experiencia de lectura con todas las ventajas del ordenador digital conectado a internet, pero con las cualidades del papel: un brillo y un contraste "natural", sin los procesos de refresco de pantalla continuos y la retroiluminación que fatigan la visión del usuario de un ordenador, y un amplio ángulo de visionado. Además aportan al dispositivo un peso muy bajo y, respecto a los demás ordenadores, un consumo de energía mínimo como resultado de su técnica biestable (las letras permanecen sin necesidad de nuevos aportes de energía). Por el contrario, las pantallas basadas en la tinta electrónica tienen desventajas graves: no permiten imágenes en múltiples colores, el refresco de la pantalla es lento, el blanco y el negro no son los de un 
buen libro y son caros de producir. Esto deja fuera a la imagen en color y al vídeo -un paso atrás respecto a las pantallas de cristal líquido que explica que algunos de los dispositivos de segunda generación todavía se comercialicen-, que son dos de las ventajas básicas de la tecnología digital, aunque, ciertamente, no son fundamentales en la lectura de libros. Es una herramienta especialmente útil para personas de viaje o en tránsito que pueden pagarse una superficie de lectura amplia y de bajo peso, y que se evitan ir cargados de libros y prensa, que pueden adquirir fácilmente desde internet. Hay que señalar que algunos lectores nocturnos siguen prefiriendo las pantallas retroiluminadas.

Las desventajas de los libros de tercera generación -color y movimiento- pueden encontrar su solución en las nuevas pantallas que están en desarrollo o empezando a entrar en el mercado, y que darán lugar a la cuarta generación de libros electrónicos. Se trata de las pantallas basadas en el efecto electrowetting -inventado en los Philips Research Labs- que han empezado a ser comercializadas por su retoño Liquavista en 2008, y las todavía carísimas de luz orgánica -conocidas como de organic light emitting diode (oled)-. Ninguna de ellas requiere iluminación posterior y soportan color y vídeo. Sin embargo, dado que se van a aplicar igualmente a los monitores de todos los tipos de ordenadores, es muy posible que estas tecnologías den al traste con buena parte de las ventajas competitivas que aportan los dispositivos dedicados actuales como el Kindle.

No obstante, el futuro del libro electrónico no está escrito. La visión de $E$ Ink, la empresa que ha revolucionado los dispositivos de lectura acercándolos a la experiencia del papel, está trabajando en el concepto de RadioPaper, un papel electrónico capaz de recibir la información de forma remota. Una tecnología de este tipo podría provocar que el ordenador portátil del futuro mediato pudiera muy bien parecer... jun libro! Un libro electrónico de bajo precio vendido con diversos formatos adecuados a diferentes fines.

En el territorio común entre los dispositivos dedicados y la lectura de libros en ordenadores convencionales se han ido desarrollando los formatos digitales de codificación de libros electrónicos, y ligados a ellos, los visualizadores. Como en otros aspectos de la informática, las empresas grandes han ido comprando los productos exitosos para ir creando o enriqueciendo sus propias aplicaciones. Ya hemos visto que Sony creó una suite de edición y un visualizador en fechas muy tempranas. Adobe dio el paso muy pronto, comprando en el año 2000 su tecnología a la empresa Glassbook, que había producido un excelente visualizador y el formato de intercambio Electronic book exchange standard (EBX) para integrarlos en Adobe Acrobat y el formato pdf. Su gran competidor, la polifacética Microsoft ela- boró sus propios estándares -LIT y la propuesta abierta Microsoft open eBook- y su visualizador -el Microsoft Reader-. PDF es un formato de página fija que en general se adapta mal a dispositivos pequeños -aunque se pueden crear ficheros adaptables-, por lo que Acrobat ha apoyado, junto con otras organizaciones como Amazon en el marco del International Digital Publishing Forum (IDPF), el desarrollo de una familia de estándares abiertos en XML -Open publication structure (OPS), Open packaging format $(O P F)$ and Open container format (OCF)-, sucesores del Open eBook publication structure (Oebps) y del OEBPS container format y actualmente en su versión 2.0. Como en otros ámbitos, la tendencia ha sido desde las soluciones propietarias a los estándares abiertos.

Que la librería electrónica es un área con un futuro cada vez mayor, complementaria de las bibliotecas digitales, lo demuestra la entrada de gigantes de internet en el sector, particularmente en 2004 el Google print library project-después Google books library projectque combina hábilmente acceso gratuito y de pago, y la buena evolución de la sección de libros electrónicos de Amazon. Lo que se dibuja es una compleja ecología en la que existirá - existe ya- un gigantesco volumen de libros digitales de libre acceso -bibliotecas digitales- junto con un mercado importante de venta por internet para novedades y colecciones retrospectivas de empresas e instituciones que sean capaces de defender activamente sus derechos de autor. Las empresas distribuidoras facilitarán enormemente el acceso, ofrecerán muchos documentos y servicios gratis, y bajarán los precios para promocionar el mercado y alcanzar un equilibrio con los consumidores y las bibliotecas, con el precio que los consumidores estén dispuestos a aceptar. La edición dual se convertirá en una excelente estrategia para ampliar el mercado de libros electrónicos aprovechando el continuo tirón del libro tradicional.

El resultado de la interacción entre todas estas tendencias es una ecología compleja (Figura 2) y sujeta a una gran competencia, en la que los diferentes productos encuentran sus nichos en virtud de sus ventajas competitivas diferenciales, y se camina en general hacia una convergencia de medios y plataformas de visualización en la que cada una encuentra su segmento de mercado.

En fin, el camino hacia el libro electrónico se apoya en la convergencia de dos grandes movimientos: uno desde el contenido -la digitalización de los libros-, y otro desde la infraestructura informática -el diseño de libros electrónicos con nuevas funciones, ya sea en dispositivos genéricos o dedicados. En este último campo se han producido avances muy importantes -pantallas de tinta electrónica y de luz orgánica, conectividad permanente, movilidad real, estandarización, interopera- 


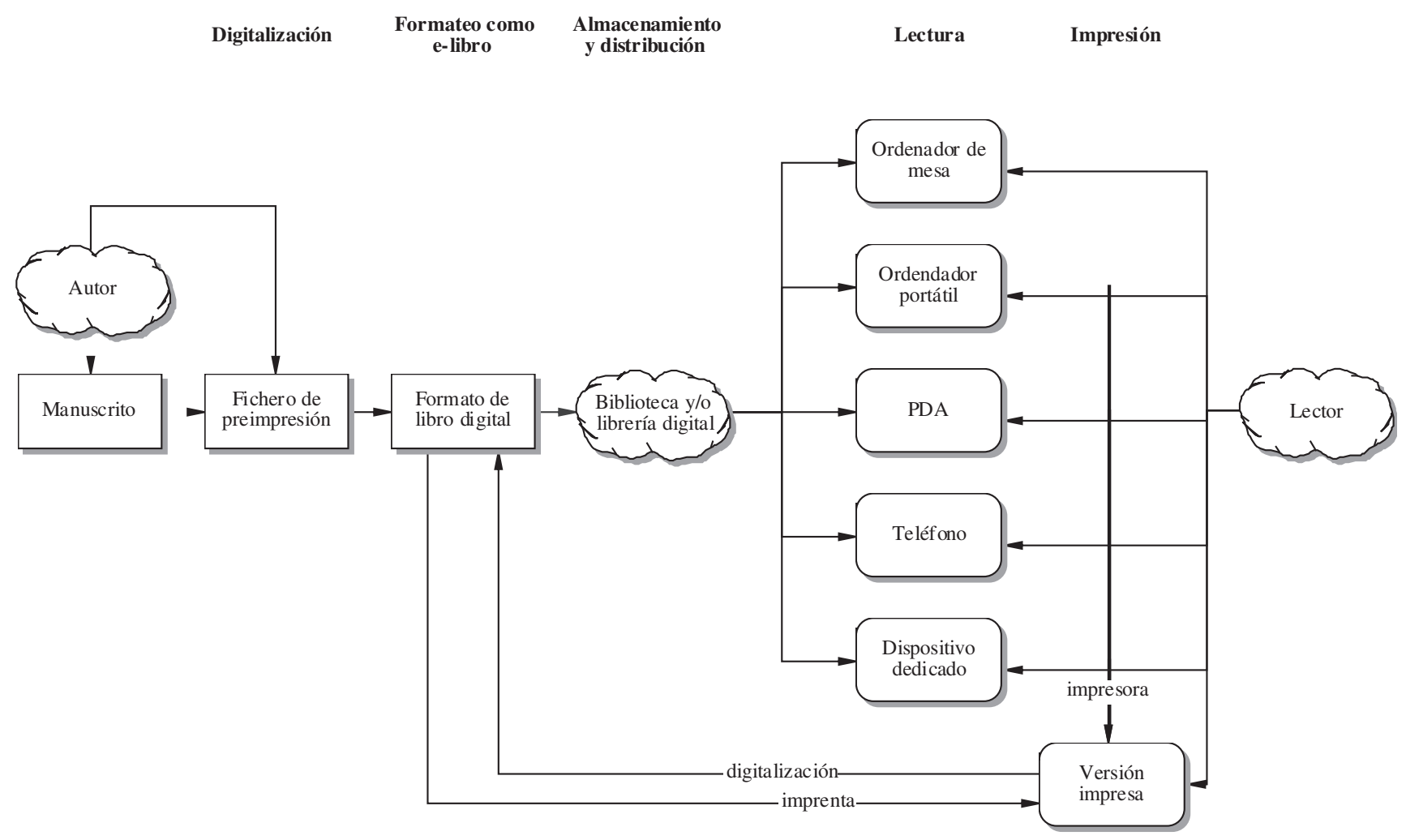

Figura 2. Las plataformas de la lectura

bilidad, integración en los catálogos-, pero limitados, amenazados continuamente por los dispositivos de carácter general, y, sobre todo, fraccionados, conformando todavía un sistema digital calidoscópico que tendrá que cuajar en una oferta integrada y bien segmentada.

\section{Características del libro: del papel al bit}

Para diseñar un libro electrónico que realmente sea capaz de superar al libro en papel, es necesario establecer claramente cuáles son las características que tiene el documento en papel que lo hacen tan valioso y único. En la práctica la definición del libro electrónico se hace por comparación entre el objeto de referencia -el libro tradicional-y la herramienta de la que se parte para suplantarlo -el ordenador electrónico más o menos adaptado-. Quiere esto decir que las tablas de características que se manejan no son exhaustivas, sino que se limitan a los aspectos diferenciales de interés para el consumidor, se trata de un benchmarking. En la tabla I se ofrece un listado exhaustivo de características para el libro en papel, el ordenador de mesa y las tres últimas generaciones de libros electrónicos.

A partir de una tabla de características, es relativamente fácil realizar una evaluación global: se trata de examinar que es lo que ha cambiado, las ventajas y los inconvenientes de libro electrónico y del analógico, y establecer que es lo que cada uno de ellos hace mejor en el momento actual. Este tipo de estudios compara- tivos han sido muy abundantes. Podemos destacar el estudio muy citado de Bill Hill (1999) y en nuestro país los de Lluís Codina (1996, 1999, 2000) para el libro digital, y la monografía de Blanca Rodríguez (2002) para el documento digital en general.

El benchmarking actual se centra en los aspectos del libro que tienen que ver con la experiencia lectora y la portabilidad, toda vez que los aspectos de formato "lógico" -tipografía, maquetación, estructura, índices y referencias, posibilidad de marcar y anotar- han sido ya trasladados con éxito al entorno digital e incluso superados mediante la automatización de la referencia y la posibilidad de abrir caminos de lectura alternativos y no lineales que proporciona el hipertexto. En cualquier caso, las características formales del libro son ya territorio compartido entre los ejemplares analógicos y digitales, al menos en la medida en que éstos se pueden virtualizar.

Las ventajas del formato papel son que resulta más cómodo de leer en un número de entornos y condiciones de luz mayores, y que es flexible, portable, resistente, biodegradable y fácilmente reciclable. Su variedad de formatos y tamaños se ajusta bien a diferentes contenidos y situaciones de lectura, y favorece en particular la lectura concentrada que acompaña al estudio y al disfrute de la ficción y el ensayo. Se adquiere por un precio dado sin costes ocultos o añadidos, y se puede utilizar durante cientos de años si recibe un cierto cuidado. Psicológicamente, resulta abarcable y tiene lími- 


\begin{tabular}{|c|c|c|c|c|c|c|}
\hline Características & & $\begin{array}{l}\text { Libro } \\
\text { en } \\
\text { papel }\end{array}$ & $\begin{array}{c}\text { Ordenador } \\
\text { de } \\
\text { mesa }\end{array}$ & $\begin{array}{c}\text { Segunda } \\
\text { generación } \\
\text { (e-portátiles) }\end{array}$ & $\begin{array}{c}\text { Tercera } \\
\text { generación } \\
\text { (e-tinta) }\end{array}$ & $\begin{array}{c}\text { ¿Cuarta } \\
\text { generación? } \\
\text { (plásticos elec- } \\
\text { trónicos) }\end{array}$ \\
\hline \multirow[t]{2}{*}{ Portabilidad } & Portabilidad general & Excelente & Muy limitada & Limitada & Aceptable & Aceptable \\
\hline & Bajo peso & $\begin{array}{l}\text { Sí, individual- } \\
\text { mente }\end{array}$ & No & Sí & Sí & Si \\
\hline \multirow[t]{7}{*}{ Experiencia visual } & $\begin{array}{l}\text { Estabilidad de la } \\
\text { imagen }\end{array}$ & Excelente & Inapropiada & Inapropiada & Excelente & Excelente \\
\hline & Contraste & Alto & Regular & Regular & Alto & Alto \\
\hline & Ángulo de visión & Natural & Reducido & Reducido & Natural & Natural \\
\hline & Resolución & Analógica & Alta & Alta & Alta & Alta \\
\hline & Superficie de lectura & Optimizada & $\begin{array}{l}\text { De calidad va- } \\
\text { riable }\end{array}$ & Limitada & Optimizada & Optimizada \\
\hline & Color & Opcional & Opcional & No/opcional & No & Sí \\
\hline & Vídeo & No & Sí & Sí & Sí & Sí \\
\hline \multirow[t]{9}{*}{ Manejabilidad } & $\begin{array}{l}\text { Conocimientos } \\
\text { requeridos }\end{array}$ & Lectura & Muy altos & Altos & \multicolumn{2}{|c|}{$\begin{array}{l}\text { Requiere conocimientos decrecientes } \\
\text { o nivelados }\end{array}$} \\
\hline & $\begin{array}{l}\text { Uso en diferentes } \\
\text { posiciones }\end{array}$ & Sí & No & Sí & Sí & Sí \\
\hline & Flexibilidad & Alta & Nula & Nula & Nula & $?$ \\
\hline & Anotar y subrayar & Sí & Sí & Sí & Sí & Sí \\
\hline & Marcado de páginas & Sí & Sí & Sí & Sí & Sí \\
\hline & Reusabilidad & Costosa & Copiar y pegar & Copiar y pegar & Copiar y pegar & Copiar y pegar \\
\hline & Computabilidad & No & Sí & Sí & Sí & Sí \\
\hline & $\begin{array}{l}\text { Interactividad de } \\
\text { usuario }\end{array}$ & No & Sí & Sí & Sí & Sí \\
\hline & $\begin{array}{l}\text { Replicabilidad (ge- } \\
\text { neración de copias) }\end{array}$ & Costosa & Marginal & Marginal & Marginal & Marginal \\
\hline \multirow[t]{2}{*}{ Autonomía } & $\begin{array}{l}\text { Independencia } \\
\text { de una fuente de } \\
\text { energía }\end{array}$ & Total & No & 7 horas & 24 horas & $?$ \\
\hline & Tiempo de arranque & No & Sí & Sí & No & No \\
\hline \multirow[t]{8}{*}{ Acceso } & $\begin{array}{l}\text { Disponibilidad inme- } \\
\text { diata }\end{array}$ & No & Sí & Sí & Sí & Sí \\
\hline & Interoperabilidad & - & No & No & Creciente & Sí \\
\hline & $\begin{array}{l}\text { Interactividad entre } \\
\text { usuarios }\end{array}$ & No & No & No & Despegando & Sí \\
\hline & \begin{tabular}{|l|} 
Conectividad perma- \\
nente a internet
\end{tabular} & No & Sí & Sí & Sí & Sí \\
\hline & Referencia & $\begin{array}{l}\text { Lenta y requie- } \\
\text { re formación } \\
\text { especializada }\end{array}$ & Inmediata & Inmediata & Inmediata & Inmediata \\
\hline & Buscabilidad & Índices & $\begin{array}{l}\text { Índices y palabras } \\
\text { clave }\end{array}$ & $\begin{array}{l}\text { Índices y palabras } \\
\text { clave }\end{array}$ & $\begin{array}{l}\text { Índices y palabras } \\
\text { clave }\end{array}$ & $\begin{array}{l}\text { Índices y palabras } \\
\text { clave }\end{array}$ \\
\hline & Control de copia & Limitado & Sí & Sí & Sí & Sí \\
\hline & Catalogación & Sí & Sí & Sí & Sí & Sí \\
\hline \multirow[t]{6}{*}{ Perdurabilidad } & $\begin{array}{l}\text { Estabilidad de la } \\
\text { codificación }\end{array}$ & Media & Alta & Alta & Alta & Alta \\
\hline & $\begin{array}{l}\text { Estabilidad del } \\
\text { acceso }\end{array}$ & Alta & Baja & Baja & Baja & Baja \\
\hline & $\begin{array}{l}\text { Durabilidad del } \\
\text { soporte }\end{array}$ & Media & Baja & Baja & Baja & Baja \\
\hline & Actualización & Costosa & Fácil & Fácil & Fácil & Fácil \\
\hline & $\begin{array}{l}\text { Obsolescencia tec- } \\
\text { nológica del soporte } \\
\end{array}$ & Muy baja & Alta & Obsoletos & Alta & Alta \\
\hline & $\begin{array}{l}\text { Disponibilidad his- } \\
\text { tórica }\end{array}$ & Reducida & Reducida & Reducida & Reducida & Total (Long tail) \\
\hline \multirow[t]{6}{*}{ Economía } & $\begin{array}{l}\text { Coste de producción } \\
\text { del soporte }\end{array}$ & Alto & Alto & Alto & Alto & Medio \\
\hline & $\begin{array}{l}\text { Coste de producción } \\
\text { del contenido }\end{array}$ & Marginal & Marginal & Marginal & Marginal & Marginal \\
\hline & $\begin{array}{l}\text { Coste de comercia- } \\
\text { lización }\end{array}$ & Alto & Alto & Alto & Medio & Medio \\
\hline & Coste de transporte & Alto & & Línea telefónica & $\begin{array}{l}\text { Internet (mar- } \\
\text { ginal) }\end{array}$ & $\begin{array}{l}\text { Internet (mar- } \\
\text { ginal) }\end{array}$ \\
\hline & $\begin{array}{l}\text { Coste de almacena- } \\
\text { miento }\end{array}$ & Alto & Marginal & Marginal & Marginal & Marginal \\
\hline & Precio de venta & $\begin{array}{l}\text { Precio de refe- } \\
\text { rencia }\end{array}$ & $\begin{array}{l}\text { Marginal en el } \\
\text { caso de todos } \\
\text { los dispositivos } \\
\text { generales }\end{array}$ & $\begin{array}{l}\text { Precio semejante } \\
\text { más el precio del } \\
\text { dispositivo, su uso } \\
\text { y su manteni- } \\
\text { miento }\end{array}$ & $\begin{array}{l}\text { Precio más bajo } \\
\text { más el del dispo- } \\
\text { sitivo, su uso y } \\
\text { mantenimiento }\end{array}$ & Precios reducidos \\
\hline
\end{tabular}

Tabla I 
tes claros como objeto, aunque a través de las referencias mantiene la relación con su entorno informativo. Cada libro es un objeto único que evoluciona por su cuenta, lo que ligado a sus cualidades artísticas -mayores o menores en distintas obras- le aporta también una valoración especial.

Por el contrario, las desventajas del libro de papel se aprecian mejor cuando se contempla en conjuntos: ocupa mucho espacio, es pesado, es costoso de producir, copiar, almacenar, conservar, transportar y distribuir, y consume recursos naturales ecológicamente valiosos. Cualquier proceso que implique movimiento requiere intervención humana. En cuanto es necesario transportar varios volúmenes, resulta incómodo, como bien sabe el viajero o el niño que va a la escuela cargado.

El libro electrónico actual tiene ya importantes ventajas. En primer lugar, un solo dispositivo permite consultar un gran número de libros y acceder a bibliotecas y librerías digitales. Los dispositivos móviles son cada vez más delgados, pesan cada vez menos -fruto de la miniaturización-, tienen más autonomía energética, consumen menos; y los que funcionan con las nuevas digitales tintas reflectoras proporcionan una buena experiencia de lectura con una luz adecuada. Como el libro digital -el fichero- es fácil y barato de almacenar, transportar y replicar, su precio puede ser la mitad o menos del de su equivalente en papel (Amazon.com). El libro digital, además, se ha estandarizado y puede circular mejor entre dispositivos; es más interoperable. Por último, puede ser protegido implementando controles de autentificación, modificación y distribución; lo que es una ventaja para los disfrutadores del derecho de copia.

Más allá de las propias características del libro en papel, que le sirve de referencia, el libro electrónico aporta las nuevas posibilidades del universo digital. Además del hipertexto y la interactividad, se abre a la convergencia multimedia con otros formatos y a la interconexión con la Red. En este sentido, el concepto de libro -y más generalmente el de documento- está recibiendo una redefinición funcional desde el multimedia. El texto se enriquece con imágenes y sonidos, y procesos interactivos automatizados, y se une casi sin transición a través de pequeños programas con el mundo de la comunicación digital, la web social.

Una de las ventajas fundamentales de la conexión a internet frente al libro tradicional es que el libro electrónico se puede distribuir en segundos y de forma automatizada. Esto es primordial para las consultas específicas y para la consulta de literatura especializada, que en papel circula lentamente. Es cierto que la distribución de libros mediante compra o préstamo ha mejorado extraordinariamente y que hoy en día tiem- pos de 24 ó 48 horas son perfectamente posibles para la mayoría de los materiales. Sin embargo, incluso ese lapso de tiempo es varios miles de veces más largo que una descarga en un ordenador.

\section{"Las desventajas del libro electrónico son, en buena parte, las del soporte: el ordenador, un dispositivo complejo y complicado, y por tanto frágil"}

Las desventajas del libro electrónico son, en buena parte, las del artefacto que le sirve de soporte: el ordenador. Como es sabido, se trata de un dispositivo complejo y complicado -y por tanto frágil- que requiere de un aporte constante de energía para funcionar; sobre las limitaciones de las pantallas actuales, ya se ha discutido anteriormente. El hardware se queda antiguo rápidamente, necesitando su sustitución periódica. Hay muchos varios costes ocultos que dependen del proveedor, como la conexión a internet. Sin embargo, en los últimos años se han visto avances muy importantes en cuanto a miniaturización, autonomía, capacidad, velocidad y simplificación del uso; y está claro que esta tecnología cada vez está más madura y que va a seguir progresando en el futuro cercano.

Un factor crítico para la adopción del libro electrónico ha sido el precio. En el caso de los dispositivos dedicados, los PDA y las tabletas, el precio ha ido bajando constantemente con relación a las prestaciones; aunque hasta el momento ha permanecido en un rango similar para los dispositivos dedicados, entorno a los 300 dólares. La presión a la baja de los precios, debido a la gran competencia y a los procesos de innovación, es muy importante en el caso de los PDA y los móviles. Además, los precios de descarga y mantenimiento se han reducido considerablemente. Los de descarga por factores asociados a los avances en las nuevas tecnologías de comunicación y la competencia entre operadores. Los de consumo eléctrico gracias a baterías más eficientes y, en el caso de los dispositivos dedicados, a la tecnología de papel electrónico -que consume mucha menos energía por tiempo de uso-. La obsolescencia del hardware y los visualizadores sigue siendo muy alta, aunque se está avanzando mucho en la estabilidad de los formatos de almacenamiento e intercambio.

\section{Impacto: la realidad del libro electrónico}

Por mucho que los análisis comparativos y evolutivos ofrezcan una perspectiva rica sobre la evolución 
del sector del libro, es fundamental aterrizar en la realidad social y ver cómo el libro electrónico y en papel se está comportando en el mercado y en las bibliotecas, que son sus dos grandes canales de distribución al usuario final. Particularmente importante es medir esta evolución en cifras para cada uno de los sectores y usos implicados, pues todos los estudios demuestran que su evolución está siendo muy diferente y que la tendencia general esconde hebras muy diversas.

\subsection{El libro digital y electrónico en el mercado}

El mercado americano es probablemente el más grande del mundo y ofrece una buena referencia para determinar como está evolucionando el libro electrónico y digital. Para hacernos una idea de las diferencias de tamaño de los mercados resulta útil una investigación de Just (2007) que establecía la existencia en 2006 de al menos 115.000 libros electrónicos comerciales disponibles en Estados Unidos -un 9\%- frente a los 5.000 en Alemania -el $1 \%$.

El citado International Digital Publishing Forum (IDPF) (2008) proporciona, conjuntamente con la $A s$ sociation of American Publishers (AAP) datos sobre las ventas mayoristas de libros digitales distribuidos por internet realizadas por entre 12 y 15 de los editores de libros electrónicos. Pues bien, desde el primer cuatrimestre del año 2002 hasta el de 2008, las ventas se han sextuplicado, y desde el primero de 2006 se han multiplicado por dos veces y media. Las ventas en los últimos años han sido:

\begin{tabular}{|c|c|}
\hline Año & $\begin{array}{c}\text { Ventas de libros-e } \\
\text { en millones de US\$ }\end{array}$ \\
\hline 2004 & 10,1 \\
\hline 2005 & 10,8 \\
\hline 2006 & 20,0 \\
\hline 2007 & 31,8 \\
\hline
\end{tabular}

Todo indica un rápido despegue del mercado americano. Otro mercado que no se queda muy atrás es el japonés. Según la Digital Content Association of Japan, las ventas de libros electrónicos para ordenadores crecieron en 2006 un 69,7\%, y, lo que es muy significativo, por móvil crecieron un 331,3\%. En este país se venden muchos comics, novelas románticas y de ciencia ficción, y es muy popular el sistema de venta por entregas, en una curiosa vuelta de este sistema tan empleado en el siglo XIX. Las ventas se orientan en buena parte a la lectura en PDAs y teléfonos móviles.

¿Cuál es la situación en España? Según el Ministerio de Cultura (2008), de 2003 a 2007 los ISBN inscri- tos para edición electrónica han crecido un 374,58\%, alcanzando los 7.503 títulos, mientras que disminuyeron ligeramente los publicados en papel. El último informe de la Federación de Gremios de Editores de España (FGEE, 2007) indica que la venta de libros en España se encuentra estancada e incluso desciende ligeramente (un $1 \%$ respecto a 2005). Significativamente, han aumentado las ventas en ciencias sociales y humanidades, divulgación general, infantil y juvenil, libros prácticos y textos no universitarios. Sin embargo disminuye la facturación de libro científico/técnico y universitario, diccionario/enciclopedias y comics, que son precisamente los sectores en donde el libro electrónico ha crecido en bibliotecas y hay una competencia fuerte en internet. Sobre todo, se lee literatura (78,2\%), aunque los porcentajes disminuyen ligeramente.

Aunque no proporciona datos sobre libros electrónicos específicamente, la Encuesta sobre equipamiento y uso de tecnologías de la información y comunicación en los hogares del Instituto Nacional de Estadística (INE) ofrece también datos complementarios sobre la penetración de la internet para la adquisición de libros, revistas y material de aprendizaje. En el segundo semestre de 2006, la adquisición de libros, revistas o material de aprendizaje electrónico fue el tercer motivo por el que los ciudadanos recurrieron al comercio electrónico $(21,6 \%)$ después de los viajes y vacaciones $(63,3 \%)$ y las entradas a espectáculos $(35,5 \%)$. En Murcia el porcentaje se eleva al 39\%, y en Melilla al $53,3 \%$. Sorprende, sin embargo, que según la $F G E E$ la venta directa por internet y correo disminuyó respecto a 2005 en un porcentaje significativo (13,8\% y 15,6\%), aunque la facturación casi se duplicó desde 2003. Los usuarios finales están empleando efectivamente más este canal $-0,7 \%$ de las compras en 2006 , por un $0,5 \%$ de los usuarios, frente a $0,4 \%$ en $2005-$, por lo que el cambio en modelos de compras debe estar afectando sobre todo a bibliotecas y compradores institucionales. Los usuarios usan conjuntamente internet y las publicaciones tradicionales: "Un 7,4\% de los lectores habituales de libros también los lee por internet. Quienes leen libros con más frecuencia suelen ser también los que dedican más tiempo a navegar por internet".

¿Ahora bien, cabe ir más allá de los datos sobre edición y compras para aproximarnos al comportamiento y la satisfacción de los usuarios? El IDPF (2006) publica un estudio de mercado que -aunque está limitado a los lectores de dos de las grandes cadenas norteamericanas, eReader.com y Fictionwise.com - resulta una mina de oro para conocer los hábitos de compra y qué piensan los compradores de libro digital:

- En cuanto a la frecuencia de uso, el $82 \%$ de los usuarios había comprado un libro en el último mes, frente a sólo un $8 \%$ que habían usado una biblioteca. 
- El 79\% leía los libros en un PDA, el 8\% en un portátil, el $7 \%$ en un PC, el $4 \%$ en un dispositivo dedicado y el $1 \%$ en un teléfono móvil.

- Un 8\% utiliza tecnología para discapacitados.

- La tasa de satisfacción sobre el material buscado fue del $75 \%$, y

- La presencia, aprecio y uso del multimedia no superó el $10 \%$.

Los principales obstáculos a la compra de libros que los usuarios señalan son el precio, la disponibilidad de títulos y la desconfianza sobre la vigencia de los formatos y la interoperabilidad (condiciones demasiado restrictivas de uso), especialmente en relación con el DRM.

Esta encuesta es también una de las pocas fuentes que permiten acercarse a la satisfacción de los usuarios de los dispositivos dedicados, que en general los valoran bien:

- La mayor parte -superando el 90\%- están satisfechos con la navegabilidad y facilidad de uso tanto del aparato como de la librería electrónica.

- Sólo el $12 \%$ considera que la lectura es peor que en el papel -un $6 \%$ la considera pobre-y sólo el $5 \%$ que son peores en cuanto a portabilidad y conveniencia de uso que el libro tradicional -el 3\% los encuentra pobres-.

- La satisfacción desciende en el precio (82\%); y, especialmente, en la capacidad de trasladar los libros entre dispositivos (78\%) o de prestarlos a los familiares y amigos (51\%), aunque este aspecto último sólo lo considera muy importante el $48 \%$.

- La satisfacción baja también para las características multimedia (69\%), la lectura en voz alta (69\%) o el uso de tecnología para discapacitados $(76 \%)$. Estas últimas características son también del interés de grupos minoritarios que no superan el $15 \%$, un porcentaje, no obstante, alto.

\subsection{El libro electrónico en las bibliotecas}

Las bibliotecas que han comprado paquetes de libros electrónicos llevan años estudiando junto con sus proveedores el comportamiento de los usuarios (Lynch, 1999; Connaway; Snyder, 2005; Safley, 2006; McKnight et al., 2008; Nicholas et al., 2007 Gregory, 2008). Estos estudios confirman muchas de las intuiciones que proporciona el análisis cualitativo, y en particular la impresión de que el libro electrónico es una tecnología que se está abriendo camino muy lentamente. Estudios muy recientes (Gregory, 2008) siguen mostrando que los estudiantes prefieren los libros en papel.

\section{"Estudios muy recientes siguen mostrando que los estudiantes prefieren los libros en papel"}

Su uso es muy limitado y la promoción entre los usuarios requiere un esfuerzo de marketing muy fuerte por parte de los distribuidores y las bibliotecas. Se ha observado en este sentido que, como ocurre con otros recursos electrónicos, resulta fundamental su inserción como un recurso más en el catálogo (Cleto, 2008) y en los buscadores -como Google-que son de la confianza de los usuarios.

Las investigaciones muestran que el libro electrónico es mejor aceptado por la gente joven, más para la lectura recreativa y la referencia -un conjunto más reducido de libros concentra la mayor parte del uso- y menos para el estudio sistemático de textos, con la notable excepción de la enseñanza a distancia, donde se está imponiendo rápidamente. Los estudiantes de tecnología, ciencias y biblioteconomía y documentación los usan notablemente más que los de humanidades, lo que se achaca a la existencia de mejores colecciones y a la mayor motivación y habilidad tecnológica (Christianson, 2005; Christianson; Aucoin, 2005). El hecho de que los estudiantes de filosofía prefieran decididamente el libro impreso apoya la idea de que la lectura de estudio intenso todavía es refractaria al libro electrónico.

Como en el caso de las revistas y como muestran los estudios de las librerías electrónicas comerciales, la masa crítica resulta ser un factor clave: cuanto más grande es la colección disponible en relación a los temas de interés, mayor uso hacen los usuarios o clientes. El factor integración en los catálogos usados por los usuarios, sean Google y otros buscadores de internet o los catálogos de las bibliotecas en las que los usuarios confían.

Por otra parte, el avance de la lectura digital en las bibliotecas españolas es ciertamente notable. Por un lado, la lectura de libros en bibliotecas digitales crece a toda velocidad. Un ejemplo relevante es la Biblioteca virtual Cervantes (Fundación..., 2008) que ha pasado de servir 324.000 páginas en julio de 1999, cuando se creó, a 16 millones en mayo de 2008, esto es, 52 veces más, y un 38,7\% respecto al mismo mes de 2007. Mientras, según Rebiun, la disponibilidad en las bibliotecas universitarias españolas del número de monografías electrónicas de pago casi se ha triplicado entre 2003 y 2007. El volumen de recursos, los proveedores y la modalidad de acceso han sido cuidadosamente estudiados por Rodríguez-Bravo, 2004; Rodríguez-Bravo y 
Alvite-Díez, 2005; Alvite-Díez y Rodríguez-Bravo, 2006; y Pérez-Arranz y Moscoso, 2007. En cuanto a las bibliotecas públicas, sabemos que los préstamos (usos) de documentos electrónicos crecieron un 158,7\% entre 2002 y 2005.

Finalmente, una reciente encuesta del Publishers Communication Group (2007) entre los directores de bibliotecas de 146 instituciones de Norteamérica, Europa y Asia ofrece el punto de vista de los bibliotecarios. Los encuestados estiman que en 2008 gastarán en recursos electrónicos el $38 \%$ de su presupuesto frente al 27\% en 2004; que sólo el $29 \%$ de sus suscripciones a revistas son únicamente en papel y que el $43 \%$ son sólo electrónicas; y que su gasto en libros digitales ha pasado de un 3,1\% en 2005 a un 6,0\% en 2006 -esto es, prácticamente se ha doblado-. Impresiona especialmente el ritmo del cambio en Asia, donde el gasto en libros electrónicos alcanza ya el 10,7\% del presupuesto. Las bibliotecas norteamericanas siguen gastando más en la adquisición de libros en papel. Por su parte, el gasto en obras de referencia está empezando a disminuir $(-0,1 \%)$ en 2008 , especialmente en Norteamérica ($0,9 \%)$, y los bibliotecarios aducen que el uso disminuye porque los usuarios prefieren internet para estas tareas. En cualquier caso, la mayor parte de las instituciones europeas $(75 \%)$ y norteamericanas $(77 \%)$ compran las obras de referencia en línea -normalmente también en papel-, frente a las asiáticas, que lo hacen menos (47\%). Contra lo que muchos esperaban, los préstamos interbibliotecarios siguen aumentando, provocando un incremento en el presupuesto dedicado a este tema del 2,7\% -un 4,3 en Norteamérica-, lo cual es un signo de que los servicios tradicionales responden también bien a las facilidades de acceso a la información y de procesamiento administrativo que proporciona internet; $y$ una muestra más de que la digitalización y el papel interaccionan de una manera compleja, no lineal.

\section{Retos y oportunidades}

Está claro que el libro digital está abriéndose camino y que gracias a los dispositivos móviles va ocupando lenta y desigualmente territorios reservados al libro en papel. También es cierto que existen restricciones tecnológicas importantes en la experiencia lectora que facilitan los ordenadores de propósito general, y que los dispositivos dedicados resultan todavía caros y limitados. Un diagnóstico parecido acaba de ser actualizado en la Digital Book 2008 -la principal feria del sector- donde los presentadores coincidían en que aún hay que recorrer un largo camino hasta que los lectores se sientan con los libros electrónicos igual de cómodos que con los libros en papel; mientras, los editores observan con interés el rápido crecimiento del mercado de libros digitales, que se están convirtiendo en una parte cada vez más importante de su negocio (Teicher, 2008).
Ahora bien, ante este panorama, ¿cómo quedan los distintos protagonistas? ¿qué motivos hay para inclinar la balanza hacia la desazón o hacia la ilusión? Porque el despegue de la digitalización en el territorio del libro no deja a nadie indiferente, y plantea diferentes retos y oportunidades a cada uno de los sectores implicados: impresores, editoriales, distribuidores, libreros, bibliotecarios, usuarios y a la sociedad en su conjunto. La ola de cambio provoca también conflictos de intereses entre las partes, de los que es un ejemplo señalado el que se está manifestando entorno al préstamo público y privado de documentos digitales.

La parte interesada que más gana es, sin duda, el usuario o consumidor, que ve multiplicadas sus opciones en todos los frentes: bajada de precios debida a las economías de escala, acceso a documentos que no podían ser comercializados en el modelo anterior, bibliotecas digitales públicas y privadas de gran tamaño, servicios añadidos ofertados por los profesionales de la información, y posibilidad de elegir los proveedores de libros y servicios que más se adecuen a sus necesidades concretas en cada momento. Los usuarios se están viendo beneficiados también por el efecto de "larga cola" descrito por Anderson (2008, ed. act.) que permite que en un entorno de distribución masiva como la internet, muchísimos más libros puedan encontrar los suficientes clientes como para generar las transacciones económicas y el beneficio de los que depende que sigan disponibles.

\section{"El efecto de 'larga cola' permite que en un entorno de distribución masiva como la internet, muchísimos más libros puedan encontrar suficientes clientes como para subsistir"}

Para la industria de la impresión del libro en papel, la digitalización supone a largo plazo un desafío total, que implica su progresiva pérdida de importancia hasta convertirse en una actividad de nicho. Paralelamente esta industria se está apoyando con notable éxito en la tecnología digital y el concepto de just in time para ofrecer servicios novedosos como la impresión bajo demanda, que lleva creciendo varios años, y para rebajar costes continuamente. Las imprentas de éxito se han convertido en servicios de publicación integrados que ofrecen preimpresión, impresión tradicional y digital conjuntamente.

El sector comercial -editoriales, distribuidoras y librerías- se mira con preocupación e interés en el espejo del mercado de la música. 
En el caso de las editoriales el principal problema gira en torno a la defensa del derecho de copia y el cuestionamiento de un modelo de negocio que había encontrado en el libro en papel un equilibro difícil pero efectivo. Un precio ajustado, una ventaja clara del soporte original frente a la copia y una política de represión de la copia ilegal dirigida contra la industria reprográfica aseguraba unos beneficios suficientes. Por otro lado, internet permite a las editoriales mejorar y automatizar la comunicación con el usuario y los procesos administrativos de la transacción económica. Como en el caso de los hoteles, la venta directa por internet permite vender a mejor precio y adaptar los productos mejor a los usuarios. También están encontrando en la denominada oferta dual -a la vez en formato electrónico y en papel- una estrategia de tránsito que, por otra parte, permite ir introduciendo a más consumidores en los nuevos formatos.

En el caso de la distribución hay que partir de que los estudios de usuario han demostrado sin lugar a dudas que el tamaño y la agregación de servicios son dos factores clave para conquistar al consumidor. Obviamente, estos factores benefician a los líderes comerciales de la Web 2.0, como Amazon. El impacto de iTunes en el caso de la música en Estados Unidos puede ser un buen ejemplo de lo que puede ocurrir cuando las tecnologías subyacentes alcancen el punto óptimo de usabilidad y satisfacción del usuario.

\section{"El tamaño y la agregación de servicios son clave para conquistar al consumidor, cosa que beneficia a los líderes comerciales como Amazon"}

Una de las ventajas añadidas de la distribución digital es que el manejo de los ejemplares está totalmente automatizado, y que se pueden ensayar muchos modelos de transacción económica: ventas con diferentes tipos de derechos -con un número determinado de copias, por ejemplo-, alquiler por un tiempo dado -útil con los libros de texto y la literatura de evasión-, suscripción a una colección por un tiempo dado, suscripción con derecho de copia de los libros usados... Esto permite un ajuste más fino al mercado, y, por lo tanto, mayores oportunidades de negocio.

Dada la movilidad de un mercado, en el que nada se da por seguro y la importancia del tamaño, la integración de edición y distribución en grupos de gran tamaño que abordan los diferentes medios está siendo desde hace años la estrategia defensiva seguida por las grandes empresas, que de paso consiguen ahorros de coste por la "sinergia" de departamentos duplicados. Sin embargo, es cierto que el rápido ritmo del cambio tecnológico y el carácter altamente automatizado de los nuevos procesos -que permiten replicar a gran velocidad, un negocio si se dispone del capital y los socios suficientes-no permiten a nadie sentirse seguro en esas industrias.

A pesar de los procesos de concentración y de "utilitarización" del mercado ${ }^{1}$, siempre quedará espacio para una extensa capa de agentes bien adaptados a la oferta y la demanda local que trabajarán desde su entorno, bien en colaboración con estas grandes empresas o actuando en sus márgenes.

Los fabricantes de libros electrónicos dedicados seguirán adoptando nuevas tecnologías y compitiendo entre sí. Sus peores competidores serán, sin duda, los fabricantes de ordenadores -de escritorio, portátiles, PDA y teléfonos móviles avanzados-, especialmente en un entorno donde la lectura es cada vez más multimedia, y la convergencia de medios es cada vez una experiencia de usuario más fuerte, amigable y demandada. Sin embargo, nada impide que se desarrollen como un mercado específico si proporcionan al usuario una experiencia multimedia, muy funcional, de bajo peso y excelente lectura a un precio muy reducido respecto a los otros dispositivos. Un aparato que permita una lectura dedicada y concentrada que minimice -permitiéndola- las tentaciones de la lectura "difusa" que propicia la navegación por internet tiene sin duda una demanda objetiva y un futuro por delante.

¿Cuál es la situación de los profesionales de la información y, especialmente, de los bibliotecarios ante esta nueva ecología? Desde hacía años (García, 1991) estaba claro que la virtualización de los soportes y la automatización de los procesos administrativos irían provocando la disminución paulatina del personal dedicado a ellos y, en el caso de los documentos digitales, del préstamo. Todavía lejana en el horizonte queda la amenaza de una nueva oleada de desintermediación del acceso -que no de la referencia especializada-, ligada a la asunción de la función de gestionar el almacenamiento y el acceso a los libros digitales por los gigantes del acceso a la internet, Google y sus competidores ${ }^{1}$. Por otra parte, las bibliotecas se ven protegidas por el hecho de que constituyen uno de los servicios de proximidad de carácter cultural que facilitan a los poderes públicos el ejercicio de la política local posmoderna.

En la reordenación de las funciones de la biblioteca que tienen que ver con el impacto del libro digital, se vislumbran claramente cinco grandes tendencias:

a) Las bibliotecas seguirán manteniendo a largo plazo la función de preservar los materiales impresos 
y grabados, y conectarlos con el nuevo medio digital. Sólo una gravísima crisis social podría dar al traste con este cometido.

b) Durante un periodo intermedio bastante largo, la bibliotecas -en cuanto que principales custodios del saber documentado- serán las principales colaboradoras en el gran proyecto de digitalización del patrimonio cultural.

c) Mantendrán en el medio plazo un importante papel en la capacitación de la población general y las audiencias especializadas en el uso y aprovechamiento de la nueva infraestructura digital, en el magno proyecto de inclusión y alfabetización digital. Muchos de los autores citados defienden con cifras elocuentes el papel de las bibliotecas como instrumento para acercar la oferta y la demanda de libros electrónicos y como un medio para que el mercado del libro-e gane tamaño.

d) Los bibliotecarios seguirán ofreciendo los servicios añadidos relacionados con gestionar el acceso digital en sus instituciones y añadir servicios añadidos como la referencia y la difusión selectiva de la información, que, bien hechos, son muy valorados.

e) Por fin, y se trata de una necesidad nueva, tendrán que enfrentarse a la magna misión de preservar la ingente marea de información digital producida por sus entornos de referencia, que en el caso de las bibliotecas responsables del depósito legal, o funciones parecidas, se extiende al conjunto de las publicaciones digitales producidas en el territorio de su jurisdicción.

Finalmente, para las culturas y las sociedades en general el libro electrónico plantea también importantes oportunidades y retos. En el haber hay que poner la aceleración de la comunicación, los efectos positivos para la especialización del trabajo, la oferta cultural y las libertades individuales. El libro electrónico, gracias a la web semántica y a la web social, se convierte en el libro automatizado e interconectado, un tercer orden respecto a las posibilidades de la comunicación presencial y documental. Los datos al alcance de la inteligencia se multiplican, las opiniones de otras personas se hacen inmediatamente disponibles, y los procesos informacionales de bajo nivel se automatizan liberando la energía humana para la creación y la toma de decisiones. Todo ello en una escala universal y a costes mínimos para los estándares actuales. Este nuevo contexto favorece la productividad, la interdisciplinariedad, el enfoque orientado a la resolución de problemas y el hallazgo feliz (véase Weinberger, 2007).

Sin embargo, existen también cuestiones problemáticas, ligadas especialmente a los efectos no deseados de la lectura hipertextual (véase Caridad; Moscoso, 1991) en océanos de información como la internet. Más allá de la sobre-información, la saturación informativa y la desorientación contextual que tanto dieron que hablar en los años ochenta y principios de los noventa, diversos autores e informes recientes creen constatar un cambio desde la cultura de la reflexión y la integración personal que propicia el libro y el documento tradicional a otra basada en la interconexión superficial y la identidad personal difusa (Marías, 1985; Ciber Group, 2007; Keen, 2007; Carr, 2008ab). Su diagnóstico -con diferentes énfasis- es que se pierde muchísimo tiempo entre una información desbordante, redundante y reverberante en el marco de una hipersocialización difusa -que también puede ser tribal-y una reducción de la profundidad personal, provocando un extraño retorno a las constricciones que planteaba a la reflexión la comunicación oral. Estas impresiones e intuiciones requieren una cuidadosa atención, aunque sea para descartarlas, y el intentar operacionalizarlas y medirlas constituye sin duda uno de los retos de la investigación para los próximos años.

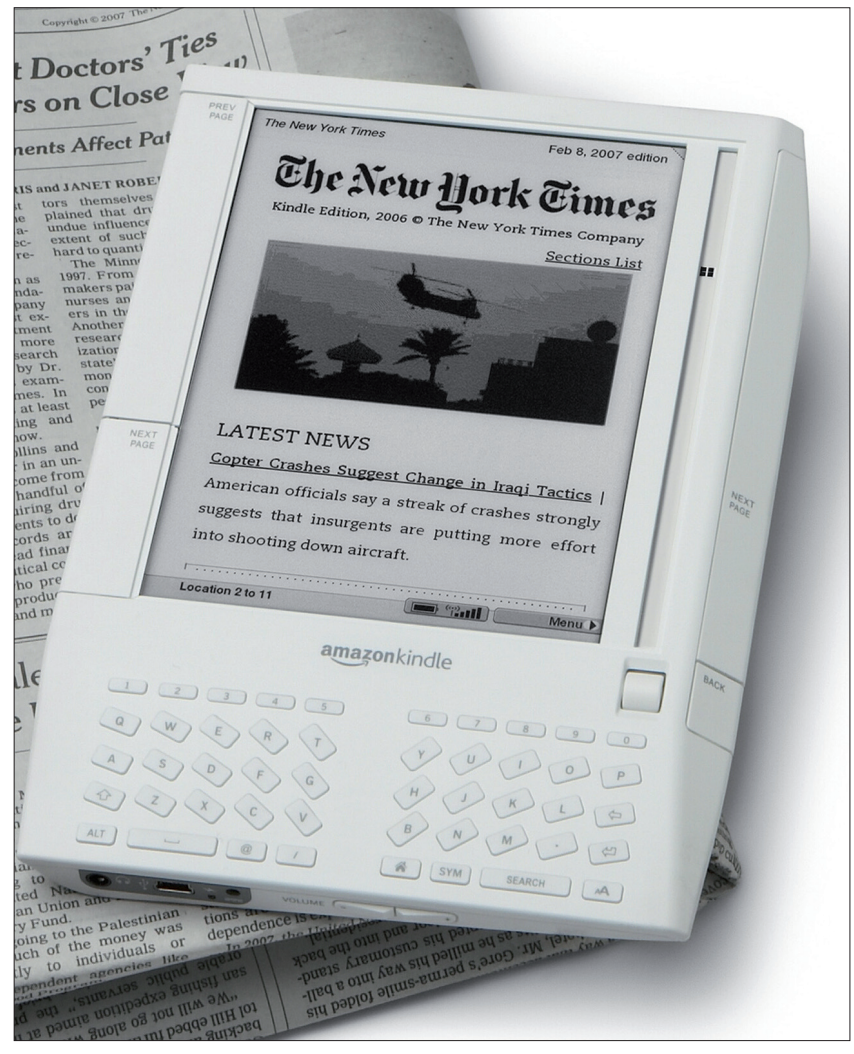

Kindle, de Amazon

Además, la naturaleza masiva del cambio que se avecina con la culminación de la digitalización -de la que el libro electrónico es sólo un frente más- deja las disyuntivas claras para todos los implicados. Los trabajadores y directivos necesitan hacer un esfuerzo añadido en su formación para permanecer competitivos, o apurar, si pueden, los años que les quedan hasta la jubilación. Las empresas deben compensar la pérdida de los mercados tradicionales reorientándose hacia los nuevos, o vender sus activos mientras aún valen algo a 
las nuevas compañías. Las organizaciones de servicio público y no gubernamentales han de cribar los modos de seguir sirviendo a sus usuarios, inventando a la vez otros nuevos, o resignarse a perder progresivamente financiación y efectivos hasta desaparecer. Y los educadores $-\mathrm{y}$ los profesionales de la información tienen cada vez más en este entorno una función educativa- se enfrentan al problema de capacitar en las nuevas formas de transmisión de la cultura a sus pupilos, pero desde un diagnóstico correcto de sus ventajas e inconvenientes.

\section{Nota}

1. La concentración de empresas e instituciones mediante fusiones, uniones y confederaciones es un hecho que apoya la visión de algunos autores sobre la conversión del mercado de la información en una nueva "utility", a la que los usuarios se enchufan de una manera parecida a lo que ocurre con la electricidad o el agua. Así por ejemplo, Carr (2008) dice que la internet se está transformando en una World Wide Computer. Otros autores insisten en los cambios que se están produciendo en este entorno de información "permanente" desde la propiedad al acceso (Rifkin, 2000), y que el motor de la nueva economía es el acceso a los recursos -en nuestro caso al libro-y ya no su posesión.

\section{Referencias}

Alvite-Díez, María-Luisa; Rodríguez-Bravo, Blanca. "Colecciones de libros electrónicos en las bibliotecas universitarias españolas". En: VIII Jornadas de gestión de la información: nuevas interfaces centradas en el usuario: tendencias en la organización de contenidos, documentos y biblioteca, 6 y 7 de noviembre de 2006, Madrid, pp. 147-159. Consultado en: 15-06-2008.

http://eprints.rclis.org/archive/00007904/

Anderson, Chris. "The long tail". En: Wired magazine, 2004, October, v. 12, n. 10. Consultado en: 15-06-2008.

http://www.wired.com/wired/archive/12.10/tail.html

Anderson, Chris. The long tail. Revised and updated. New York: Hyperion, 2008.

Caridad, Mercedes; Moscoso, Purificación. Los sistemas de hipertexto e hipermedios: una nueva aplicación en informática documental. Salamanca; Madrid: Fundación Germán Sánchez Ruipérez; Madrid: Pirámide, 1991.

Carr, Nicholas G. "Is Google making us stupid?". En: Atlantic monthly, 2008, July/August. Consultado en: 15-06-2008.

http://www.theatlantic.com/doc/200807/google

Carr, Nicholas G. The big switch: rewiring the World, from Edison to Google. York: W. W. Norton \& Co., 2008.

Christianson, Marilyn. "Patterns of use of electronic books". En: Library collections acquisitions \& technical services, 2005 , v. 29 , n. 4, pp. 351363.

Christianson, Marilyn; Aucoin, Marsha. "Electronic or print books: which are used?". En: Library collections acquisitions \& technical services, 2005, v. 29, n. 1, pp. 71-81.

Ciber Group, University College London. Google generation. London, JISC; British Library, 2007. Varios archivos. Consultado en: 15-06-2008.

http://www.jisc.ac.uk/whatwedo/programmes/resourcediscovery/googlegen. aspx

Cleto, Cynthia. "ATG Special report - 10 steps to implementing an eBook collection: A guide for librarians". En: Against the grain, 2008, February, v. 20 , n. 1 , pp. $47-48$.

Codina, Lluís. "El libro digital y el territorio de la lectura". En: El profesional de la información, 1999, enero febrero, v. 8, n. 1-2, pp. 4-6.

Codina, Lluís. El libro digital y la www. Madrid: Tauro Ediciones, 2000. 274 p.

Codina, Lluís. El llibre digital: una exploració sobre la informació elec- trònica i el futur de l'edició. Barcelona: Generalitat de Catalunya, Centre d'Investigació de la Comunicació, 1996. 191 p.

Connaway, Lynn Silipigni; Snyder, Clifton. "Transaction log analysis of electronic (e-book) usage". En: Against the grain, 2005, February, pp. 8589. Consultado en: 15-06-2008.

http://www.oclc.org/research/publications/archive/2005/connaway-snyder-atg.pdf

Digital Content Association of Japan. Digital content white paper. Tokyo: DCAJ, 2006.

E Ink Corporation. Electronic paper displays. Cambridge, MA: E Ink Corporation, 1997-2005. Consultado en: 15-06-2008. http://www.eink.com

Eíto-Brun, Ricardo. "El camino hacia el libro electrónico". En: El profesional de la información, 2002, v. 11, n. 1, pp. 52-63. Consultado en: 15-06-2008.

http://www.elprofesionaldelainformacion.com/contenidos/2002/enero/7.pdf

España. Jefatura del Estado. "Ley 10/2007, de 22 de junio, de la lectura, del libro y de las bibliotecas". En: Boletín oficial del Estado, 23/6/2007, n. 150, pp. 27140-27150.

Federación de Gremios de Editores de España. Informe del sector editorial 2006. [Madrid: FGEE, 2008]. Consultado en: 15-06-2008.

http://www.federacioneditores.org/0_Resources/Documentos/Informe_Sector_ editorial2006.pdf

Ferguson, Chris. "Technology left behind - eBook rollout". En: Against the grain, 2006, November, v. 18, n. 5. Consultado en: 15-06-2008.

http://www.against-the-grain.com/TOCFiles/ebookrollout.pdf

Ferguson, Chris. "Technology left behind - eBook rollout". En: Against the grain, 2007, November, v. 19, n. 3. Consultado en: 15-06-2008. http://www.against-the-grain.com/_old/ebookrollout/

Fundación Biblioteca Virtual Miguel de Cervantes. Información: estadísticas [Alicante: FBVMC, 2008]. Consultado en: 15-06-2008.

http://www.cervantesvirtual.com/informacion/estadisticas.jsp

Gall, James E. "Dispelling five myths about e-books". En: Information technology and libraries, 2005, March, v. 24, n. 1, pp. 25-31 March 2005. Consultado en: 15-06-2008.

http://www.ala.org/ala/lita/litapublications/ital/volume242005/number1 march/contentabc/roel.pdf

García-Marco, Francisco-Javier. "Las bibliotecas y sus recursos humanos ante las nuevas tecnologías". En: Asociación Andaluza de Bibliotecarios. Actas de las X Jornadas Bibliotecarias de Andalucía. Málaga: Asociación Andaluza de Bibliotecarios, 1998, pp. 9-51.

Gregory, Cynthia L. "But I want a real book: An investigation of undergraduates' usage and attitudes toward electronic books". En: Reference \& user services quarterly, 2008, Spring, v. 47, n. 3, pp. 266-273.

Hill, Bill. The magic of reading. [Washington]: Slate Magazine, 1999. Consultado en: 15-06-2008.

http://slate.msn.com/ebooks/magic.lit

Instituto Nacional de Estadística. Encuesta sobre equipamiento y uso de tecnologías de la información y comunicación en los hogares: Uso de comercio electrónico con fines privados o para el hogar en los últimos 12 meses por Comunidades Autónomas y tipo de producto. Resultados por CC.AA. Madrid: INE, 2008. Consultado en: 15-06-2008.

http://www.ine.es/

International Digital Publishing Forum. Ebook user survey 2006. IDPF, February 2006. Consultado en: 15-06-2008.

http://www.openebook.org/doc_library/surveys/IDPF_eBook_User_Survey_ 2006.pdf

International Digital Publishing Forum. Wholesale eBook Sales Statistics. IDPF, 2008. Consultado en: 15-06-2008.

http://www.openebook.org/doc_library/industrystats.htm

Just, Peter. "Electronic books in the USA - their numbers and development and a comparison to Germany". En: Library Hi Tech, 2007, v. 25, n. 1, pp. 157-164.

Keen, Andrew. The cult of the amateur: how today's internet is killing our culture. 1st ed. New York: Doubleday/Currency, 2007.

López-Yepes, José. El estudio de la documentación. Madrid: Tecnos, 1981. 
Lynch, Clifford. "Electrifying the book". En: Library journal, 1999, Oct. 15 , v. 124, n. 17 supplement, p. 4.

Marías, Julián. Cara y cruz de la electrónica. Madrid: Espasa-Calpe, 1985.

McKnight, Cliff; Dearnley, James; Morris, Anne. "Making e-books available through public libraries: some user reactions". En: Journal of librarianship and information science, 2008, v. 40, n. 1, pp. 31-43.

Ministerio de Cultura. Panorámica de la edición en España: Edición en otros soportes. Cuadros de evolución. Madrid: MCU, 2008. Consultado en: 15-06-2008.

http://www.mcu.es/libro/MC/PEE/estadisticas/soportesEvo.html

Nicholas, David; Huntington, Paul; Rowlands, Ian. "E-books: how are users responding?". En: Library \& information update, 2007, Nov, v. 6, n. 11 , pp. 29-31.

Pedraza-Gracia, Manuel-José. "Bibliología (ciencia del libro) y Ciencias de la Documentación”. En: Scire: representación y organización del conocimiento, 2005, en.-jun., v. 11, n. 1, pp. 27-46.

Popper, Karl-Raimund. Objective knowledge: an evolutionary approach. Rev. ed. Oxford: Clarendon Press; New York: Oxford University Press, 1979.

Publishers Communication Group. Library budget predictions for 2008: results from a telephone survey August 2007. [Cambridge; Oxford]: PCG, November 2007. Consultado en: 15-06-2008.

http://www.pcgplus.com/Resources/LibraryBudgetSurvey2008.pdf

Real Academia de la Lengua Española. Diccionario de la lengua española. $22^{\mathrm{a}}$ ed. y avance de la 23 ${ }^{\mathrm{a}}$. Madrid: Real Academia de la Lengua Española, 2001-2008. Consultado en: 15-06-2008.

http://buscon.rae.es/draeI/

Rifkin, Jeremy. La era del acceso: la revolución de la nueva economía. Barcelona: Paidós, 2000.

Rodríguez-Bravo, Blanca. El documento: entre la tradición y la renova- ción. Gijón: Trea, 2002. 281 p.

Rodríguez-Bravo, Blanca. Evaluación del acceso y gestión de los libros electrónicos en las bibliotecas universitarias españolas. Madrid: Ministerio de Educación, Cultura y Deporte. Programa de estudios y análisis destinado a la mejora de la calidad de la enseñanza superior y de la actividad del profesorado universitario, 2004. Consultado en: 15-06-2008.

http://wwwn.mec.es/univ/html/informes/estudios_analisis/resultados_2004/ ea0115/ea0115.pdf

Rodríguez-Bravo, Blanca; Alvite-Díez, María-Luisa. "Survey of the providers of electronic publications holding contracts with Spanish university libraries". En: D-Lib magazine, 2005, April, v. 11, n. 4. Consultado en: 1506-2008.

http://www.dlib.org/dlib/april05/alvite/04alvite.html

Safley, Ellen D. "Tearing down the walls: demand for e-books in an academic library". En: Libraries without walls. London: Facet Publishing, 2006, pp. 224-232.

Teicher, Craig-Morgan. "The customer is king at digital book 2008". En: Publishers weekly, 5/15/2008. Consultado en: 15-06-2008.

http://www.publishersweekly.com/article/CA6561155.html?nid=2286\&sou rce $=$ title $\&$ rid $=257945418$

Van Roekel, James L. "Electronic books: portable access to digital information". En: Achleitner, Herbert K.; Dimchev, Alexander (eds.). Libraries in the age of the internet: papers from the international conference held in Sophia, Bulgaria, 8-10 November 2000. Sofía: Union of Librarians and Information Services Officers, 1991. 290-7.

Weinberger, David. Everything is miscellaneous: the power of the new digital disorder. 1st ed. New York: Times Books, 2007.

Francisco-Javier García-Marco, Universidad de Zaragoza, Área de Biblioteconomía y Documentación, Pedro Cerbuna, 12. 50009 Zaragoza.

jgarcia@unizar.es
Recuiso electrónico que contiene en su base de datos en línea textos completos publicados por 50 editoriales italianas entre las más prestigiosas en las materias de Humanidades y Ciencias sociales

\subsection{Textos completos}

2.700 Monografías y Actas de congreso

- 200 Revistas
Casalini Libri

Via Benedetto da Maiano 3 50014 Fiesole (Florencia) - Italia Tel. +39055 50181 Fax +39055 5018201 www.casalini.it
Informaciones:

angels.escursell@casalini.it 